\title{
Identification of Potential Groundwater Bearing Zones by Hydrostratigrafic Analysis in the Eastern Part of Kushtia District
}

\author{
M. Shahinuzzaman, M. Nasir Uddin Khan, Md. Khairul Islam and Md. Zahidul Islam
}

\begin{abstract}
The study was conducted to analyze the groundwater potential zones in the Eastern part of Kushtia district. Secondary data collected from Bangladesh Agriculture Development Board Corporation (BADC) and borehole data of 119 locations have been processed, analyzed and interpreted for studying the hydrogeological properties. The sub-surface groundwater-bearing sequence of the area up to the depth of $97 \mathrm{~m}$ have been classified into two main hydrostratigraphic unitsaquitard and aquifer, consisting of clay-silt-sand and sands of different granular respectively. The 18-30 m thick aquitard is covering a major part of the study area. The thickness of main aquifers is varying from $0.9-30 \mathrm{~m}$ and $27-67 \mathrm{~m}$ consisting of fine-medium to coarse sand. The yield potential index is 1.3-13.0. However, from the obtained results, it can be concluded that the area is suitable for groundwater potentiality.
\end{abstract}

Index Terms - Hydrostratigraphic, Groundwater resources, Water bearing zones, Hydrostratigraphic correlation, Yield Potential Index.

\section{INTRODUCTION}

$\mathrm{W}$ ATER is life for all the living things on this planet. It is mostly used and wasted by the human being. The ever-increasing population has put extra pressure on the freshwater and purest form of which is found as groundwater. Demand for fresh water is very high for domestic, irrigation and industrial purpose in and around the world as well as in an agro-based country like Bangladesh. But lack of proper knowledge and research about groundwater availability put many

\section{DOI: https://doi.org/10.3329/gubjse.v7i0.54019}

This paper was received on 20 May 2020, revised on 11 March 2021 and accepted on 19 April 2021.

M. Shahinuzzaman is with the Department of Electrical and Electronic Engineering, Islamic University, Kushtia, Bangladesh. E-mail: shahin.aece@gmail.com.

M. Nasir Uddin Khan is with the Department of Electrical and Electronic Engineering, Islamic University, Kushtia, Bangladesh. E-mail: mnukhan@gmail.com.

Md. Khairul Islam is with the Department of Electrical and Electronic Engineering, Islamic University, Kushtia, Bangladesh. E-mail: khairul.aeceiu@gmail.com.

Md. Zahidul Islam is with the Department of Department of Information and Communication Technology, Islamic University, Kushtia, Bangladesh. Email: zahidimage@gmail.com. places of Bangladesh to water scarcity at an alarming rate [1]. The continuous decline of the water level has already made many fertile lands to the barren land and forced many peasants to change occupation and change crop patterns [2]. So intensive investigation is the demand for time in my study area, so in many places in Bangladesh. The location of the present study is on the upper side of the Ganges river dependent area, southwest of Bangladesh. This area is almost non-industrialized and dependent on the agricultural system characterized by several agroeconomical and socio-economic variables. Land with ensured irrigation is closely related to the development of agriculture of the study area.

Foods for the ever-increasing population putting intense pressure on available lands [3]. It is found over the years that freshwater availability is reduced to almost zero during winter and a major part of summer when lands are cultivated for vegetables, rice, wheat and many other crops. But, this reduction of freshwater flows in the Ganges river during very low or no rainfall period in recent years has limited the possibility of surface water resources development, which enhancing the people of the area to progressively shift to groundwater-dependent irrigation-based agriculture [4]-[5]. Ultimately people had to look for alternative freshwater sources where groundwater plays a very important role. It is quite sure that future freshwater demands for domestic use and irrigation will be achieved through the development of groundwater resources of the area. Therefore, the assessment of the hydrogeological or geo-hydrological condition of the study area is essential to identify the groundwater potentiality of the aquifer system for the future development of the growing needs of the increasing population.

Hydrostratigraphy is one of the element of stratigraphy that deals with the groundwater- bearing units. Hydrostratigraphic units are classified into aquifer or aquitard. The distribution of aquifers and aquitards in a geological system is controlled by lithology, stratigraphy and structure of the geologic formations. In unconsolidated deposits, the lithology and stratigraphy constitute the most important controls.

In this work, the hydrostratigraphic investigation has been done for the identification of groundwater 
bearing zones for the future development of groundwater resources of the area studied. Borehole lithologs data and pumping test data from 119 locations in the eastern part of greater Kushtia district of Bangladesh have been used for this purpose. Groundwater yield potential at different locations has also been estimated for spatial assessment of groundwater potential along with the properties of operating water-wells in the study area namely radius of in fluence is also studied.

\section{FEATURES OF THE STUDY AREA}

Study area is located in the Eastern part of Kushtia district encompassing three Upazilas (Sub-districts) namely, Khoksha and Northern parts of Kushtia Sadar and Kumarkhali. [Fig.1] (Longitude $89^{\circ} 4^{\prime} 50^{\prime \prime}-89^{\circ} 22^{\prime} 5^{\prime \prime} \mathrm{E}$ and Latitude $23^{\circ} 43^{\prime} 45^{\prime \prime}-23^{\circ} 57^{\prime} 4^{\prime \prime}$ N). The study area comprising of $292.3 \mathrm{~km}^{2}$ of the eastern part of the Kushtia district situated in the upper side of the lower Ganges delta. The Padma (the Ganges) and the Gorai are the major sources of surface water in the area. These rivers are providing sustainability for the environment and development of the area in a socio-economic perspective.

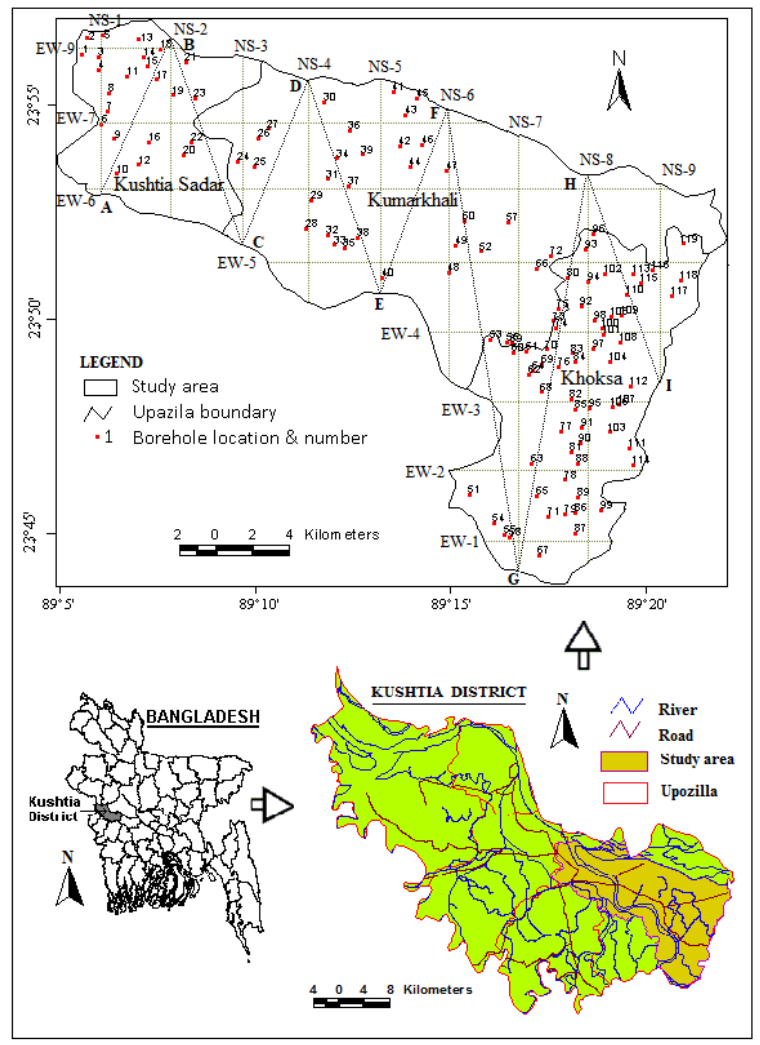

Fig: 1 Study area.

Most of the area is low lying floodplain formed by the alluvial soil. The alluvium is composed mostly of clay-silt-sand, fine sand and is gray and brown in color [6]. The country's largest surface water irrigation project- "The Ganges-Kabadak" (G-K) that supplies water flows from the Ganges is located to the south and west sides of the study area.
Several research works have been carried out by several authors in and around the study area. Groundwater potentiality were investigated in term of aquifer system[6], subsurface formation[7], hydrogeological properties[8], Geoelectrical sounding, borehole litholog and groundwater data[9]. All the previous researches were mostly focused on the overall assessment of hydrogeology of the area. No research has been carried out so far on the spatial assessment of groundwater potential in the area.

\section{MATERIALS AND METHODS}

As the population increases more water will be required for agriculture, industry and domestic purposes. Groundwater in most parts of the country particularly in the study area is believed to be overexploited. Falling water level, reduction in seepage, are manifestations that indicate that the management of this precious resource is not adequate. The groundwater resource management is vital for the human survivor and is not feasible unless a complete assessment of the system is made. Litholog is one of the major sources of valuable data for hydrogeological studies. Total of 119 boreholes data of the area collected from BADC. With the aid of Rorkworks/2004 (version 6.6.26), SURFER (version 8.00) collected data have been processed, analyzed and interpreted for quantitative hydrogeological studies. The litholog data are densely distributed in the eastern, western and middle zones of the area, whereas the data in the middle-east and middle-west zones are coarsely distributed (Fig.1). The sub-surface geology has been effectively studied. Some studies attempted to the maximum depth of $97 \mathrm{~m}$. Lithological data are used to study stratigraphy, hydrostratigraphic units, groundwater bearing zone, and spatial assessment of groundwater yield potential in the study area.

\section{RESULTS AND DISCUSSION}

\section{STRATIGRAPHY}

A. The 3D models and each layer of the area has been prepared using Rorkworks/2004 (version6.6.26) software are shown in Fig. 2. To observe the stratigraphy in various parts of the area different representative fence diagrams along the profiles of north-south, east-west and ABCDEFGHI directions have been prepared and presented in Fig. 3. The heights of different layers depicted in figures here were referenced to mean sea level (msl). The entire area consisting of sub-surface layers with different grain size. The names are top clay-silt-sand layer and sandy layer. Further sandy layers are categorized as fine, fine-medium, medium, medium-coarse and coarse sand. Almost everywhere sands of three categories from sandy layers along with clay-sit-sand were found, but medium and medium-coarse sands were not observed ubiquitously in the area. 
The overall thickness of the multi-layered waterbearing formations of the area used as a productive aquifer is suitable. From these figures, it could be concluded that the sub-surface geology of the area is favorable for groundwater development provided the other conditions are satisfied.

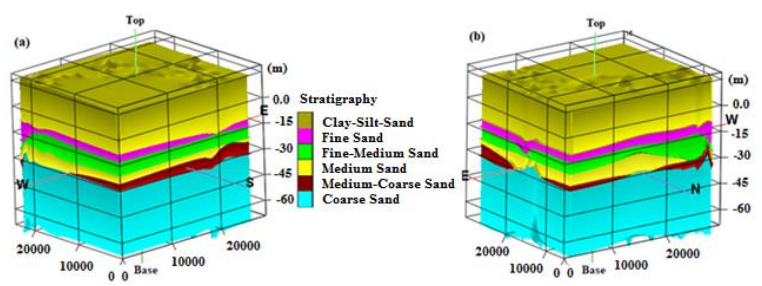

Fig. 2 Three-dimensional stratigraphic model viewing from (a) the southwest corner and (b) northeast corner.

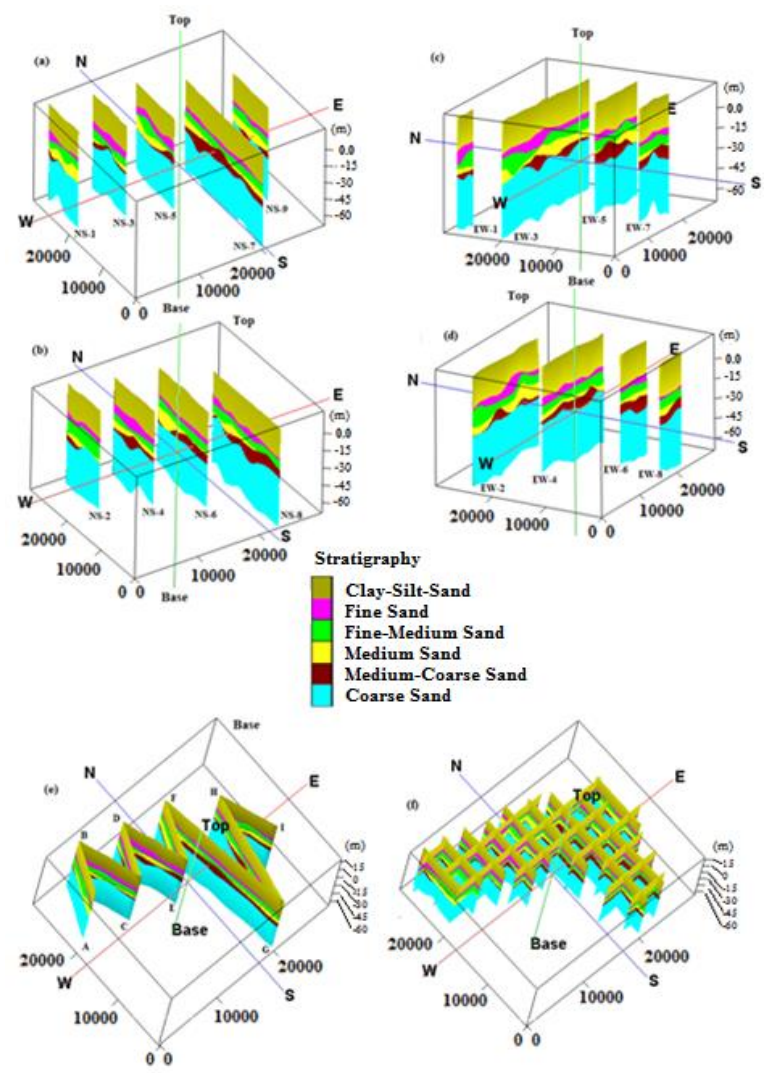

Fig. 3 Fence diagram (a) NS-1, NS-3, NS-5, NS-7, NS-9, (b) NS-2, NS-4, NS-6, NS-8 along north-south directions (c) EW-1, EW-3, EW-5, EW-7; and (d) EW-2, EW-4, EW-6, EW-8 along east-west directions, and (e) ABCDEFGHI, and (f) north-south and east-west directions.

\section{B. HYDROSTRATIGRAPHIC UNITS}

Hydrostratigraphic units are classified into aquifer or aquitard units [10] - [12]. A total of 6 sandy layers have been merged into three layers where clay-siltsand stays as first layer which is considered as aquitards, fine sand as second layer and small-scale aquifer. Finally, the rest of the 4 layers formed the third layer as main aquifer and sub-regional stratigraphic sections along ABCDEFGHI based on thickness and disposition of lithologic units are shown in Fig. 4. The sectional views clearly distinguish the earth's surface elevation and thickness of different litho units.

\section{AQUITARDS}

Geologic deposits with very low hydraulic conductivity are known as aquitards. Lateral variation of the thickness of the aquitard is shown in Fig. 5.

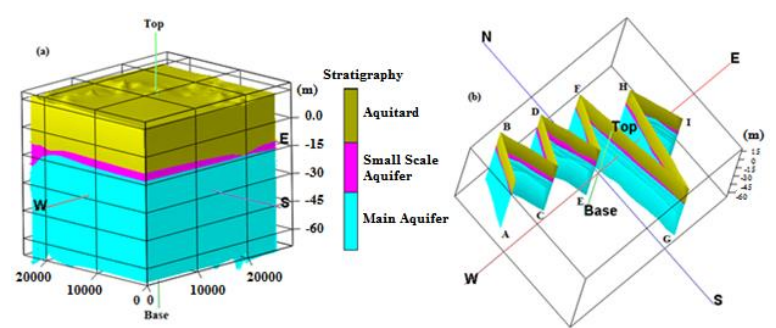

Fig. 4 (a) Reconstructed three-dimensional stratigraphic model of the study area viewing from the southwest corner (b) Fence diagram along ABCDEFGHI.

Most of the area lies within the thickness of $18-30 \mathrm{~m}$, whereas $6-18 \mathrm{~m}$ thick zone is prevailing in the middle as a pouch. The high thick beds of 30-37 $\mathrm{m}$ are distributed in a different part of the area. As the permeability and productivity of this layer is very low this layer may be used as the groundwater source only for the dug wells.

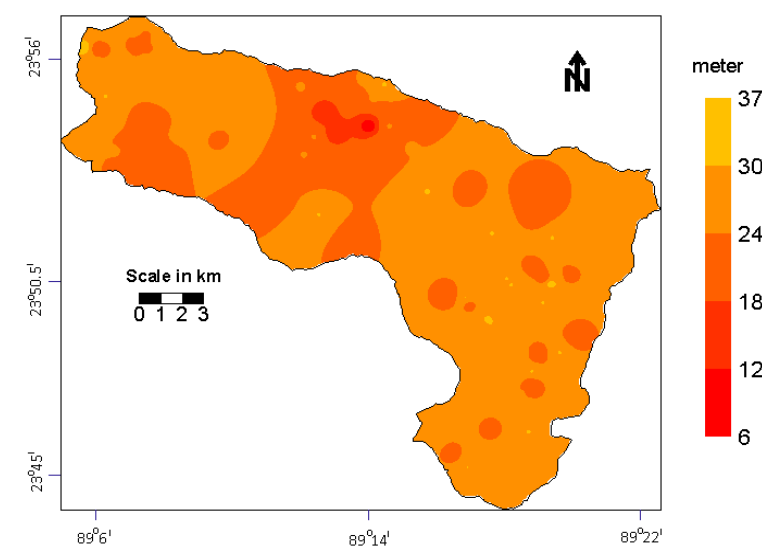

Fig. 5 Lateral variation of the thickness of first layer.

\section{AQUIFER}

Fine medium, medium, medium-coarse and coarse sand of different granular sizes indicated the presence of aquifers which were confirmed with lithological data of the area. Aquifers were sub-divided as (i) small scale aquifer and (ii) main aquifer.

(i) Small-Scale Aquifer: Lithological data of the area affirm that a layer consisting of fine sand present almost everywhere just below the top aquitard layer. The spatial distribution of depth and thickness of the aquifer is shown in Fig. 6. Depth and thickness vary from 6-36 $\mathrm{m}$ and $0.9-30 \mathrm{~m}$ respectively. The 18-30 $\mathrm{m}$ depth covers the most of the area (Fig. 6(a)), but the rest area prevails depth of 6-18 m located in the middle as well as a depth of 30-36 m distributed in the area as very small pockets. Almost $90 \%$ area 
occupies within the thickness of $6-12 \mathrm{~m}$ and the rest of the area lies within the thickness of $12-30 \mathrm{~m}$ and 0.9-6 m (Fig. 6(b)).

Due to medium permeability and productivity, this layer might be used for small-scale groundwater abstraction. This layer is well fitted for dug wells, shallow and hand tube wells water source.

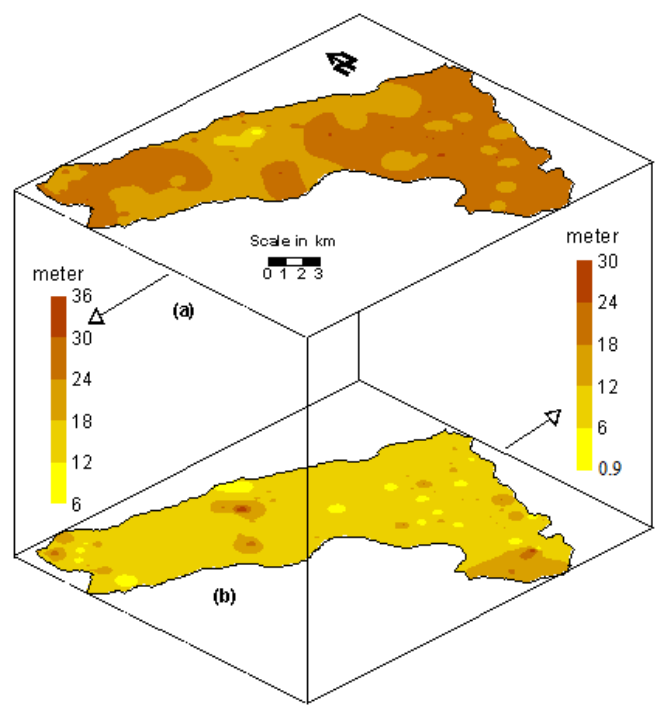

Fig. 6 Spatial distribution of (a) depth and (b) thickness of the small-scale aquifer.

(ii) Main Aquifer: In the investigated area, a lower and larger layer formed after the merger of four sand types with relatively larger granular size serves as a potential layer for groundwater storage, distribution and exploration. The spatial distribution of the depth and thickness of the main aquifer have been prepared using lithological information (Fig. 7). The thick bed of $27-67 \mathrm{~m}$ is distributed in the area within the depth of $18-55 \mathrm{~m}$. A more thick bed of 43-67 m covers almost $85 \%$ of the area. The presence of a thick bed of the main aquifer indicates a favorable condition for groundwater development if the other conditions are satisfied.

A generalized hydrostratigraphic succession for the study area is proposed based on the chronology of different formations as revealed in hydrostratigraphic cross-sections. This has been presented in table 1 .

\section{E. HYDROSTRATIGRAPHIC CORRELATION}

The sequence stratigraphy provides a potential prediction of groundwater. The vertical boundary of hydrostratigraphic and lateral boundary of lithostratigraphic units are designated on the basis of significant breaks in their characteristics as are identifiable and traceable in the field [13].

\section{F. YIELD POTENTIAL INDEX}

The total aquifer to aquitard thickness ratio, termed as yield potential index, is presented in Fig. 8. Three distinct type yield potential zones have been demarcated in the study area. The yield potential index varies from 1.3-13.0. The index value less than 3.0 covering almost $80 \%$ of the area indicate a good groundwater potential zone, whereas yield potential index of 3.0-6.0 located mainly in the middle and as small pouches distributed in different parts of the area indicate a very good potential zone. A very small pocket situated in the middle with a high yield index greater than 6.0 is proposed as an excellent yielding zone.

Table 1. Hydrostratigraphic correlation.

\begin{tabular}{|l|c|c|c|}
\hline \multicolumn{1}{|c|}{$\begin{array}{c}\text { Lithologic } \\
\text { Description }\end{array}$} & $\begin{array}{c}\text { Depth } \\
(\mathrm{m})\end{array}$ & $\begin{array}{c}\text { Thickness } \\
(\mathrm{m})\end{array}$ & $\begin{array}{c}\text { Aquifer } \\
\text { types }\end{array}$ \\
\hline $\begin{array}{l}\text { Clay with silt } \\
\text { and sand }\end{array}$ & 0 & $6-36$ & Aquitard \\
\hline Fine sand & $6-36$ & $0.9-30$ & $\begin{array}{c}\text { Small- } \\
\text { scale } \\
\text { Aquifer }\end{array}$ \\
\hline $\begin{array}{l}\text { Fine-medium, } \\
\text { medium, } \\
\text { medium- } \\
\text { coarse and } \\
\text { coarse sand }\end{array}$ & $18-55$ & $27-67$ & $\begin{array}{c}\text { Main } \\
\text { Aquifer }\end{array}$ \\
\hline
\end{tabular}

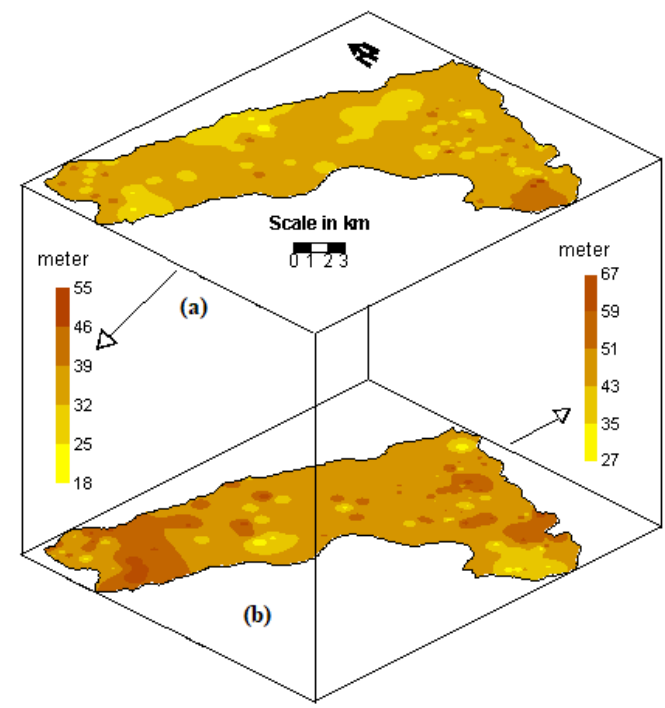

Fig. 7 Spatial distribution of (a) depth and (b) thickness of the main aquifer.

\section{CONCLUSION}

The subsurface discreteness in the Eastern part of the greater Kushtia district has been studied from borehole lithologs. Referenced to lithological and hydrostratigraphic information these layers merged to only three layers which were further divided into aquitard and aquifer. Lower aquifers having a thickness of $18-30 \mathrm{~m}$ might be used for different dug wells underground water source covers most of the area. The aquiferic materials of different granular confirm a 'small-scale aquifer' composed of fine sand underlain just below the top aquitard, and a 'main 
aquifer' consisting of fine-medium to coarse sand. Depth of the small-scale aquifer varied from $6 \mathrm{~m}$ to 36 $\mathrm{m}$ and thickness from $0.9 \mathrm{~m}$ to $30 \mathrm{~m}$ respectively.

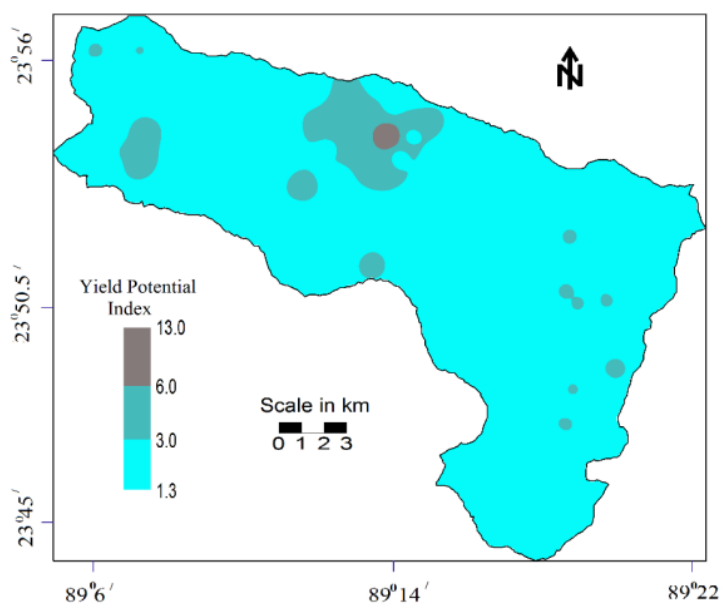

Fig. 8 Groundwater yield index map of the study area

The fluctuations of the water table were observed within the aquitard throughout the year. Considering the development potential of groundwater in the area, the main aquifer having a thickness of 43-51 m can be considered as the most productive layer. Groundwater yield potential map for the area has been prepared in terms of yield potential index defined as the ratio of aquifer to aquitard. The yield index of 1.30 to 13.0 confirms that the area is aquifer dominating. So, it can be concluded that this area is suitable for groundwater development.

\section{REFERENCES}

[1] M. A. Rahman and M. N. Islam, "Scarcity of Safe Drinking Water in the South-West Coastal Bangladesh", J. Environ. Sci. \& Natural Resources, 11(1\&2), pp. 17-25, 2018.

[2] M. A. Mojid, M. F. Parvez, M. Mainuddin and G. Hodgson, "Water Table Trend-A Sustainability Status of Groundwater Development in North-West Bangladesh", Water. 11:1182, 2019. DOI:10.3390/w11061182.

[3] P. K. Streatfield and Z. A. Karar, "Population Challenges for Bangladesh in the Coming Decades", $J$ Health Popul Nutr. Sep 26(3), pp 261-272, 2008.

[4] M. M. Q. Mirza, "Diversion of the Ganges Water at Farakka and Its Effects on Salinity in Bangladesh", Environmental Management, 22(5), pp. 711-722, 1998 DOI: $10.1007 / \mathrm{s} 002679900141$.

[5] A. K. Gain and C. Giupponi, "Impact of the Farakka Dam on Thresholds of the Hydrologic Flow Regime in the Lower Ganges River Basin (Bangladesh)", Water. 6 pp. 2501-2518, 2014. DOI:10.3390/w6082501.

[6] M. N. Haque and M. A. F. M. R. Hasan, "Groundwater potentiality in the western part of Kushtia district, Bangladesh", Journal of Applied Science and Technology, Islamic University, Kushtia, Bangladesh, 2(1), pp. 93-99 2001.

[7] M. N. Haque and M. A. F. M. R. Hasan, "Sub-surface formations and groundwater flow in Daulatpur and Bheramara thana of Kushtia district, Bangladesh", Journal of the Bangladesh National Geographical Association, Bangladesh. 30(1-2), pp. 41-54, 2002.

[8] M. S. Islam, M. N. Haque and M. A. F. M. R. Hasan, "Hydrogeological conditions in the northern part of Kushtia Sadar Upazila of Bangladesh", Journal of Geo-
Environment, Rajshahi University, Bangladesh., vol. 1, pp. 79-89, 2001.

[9] M. N. Haque, M. Keramat and S. Shahid, "Groundwater resource evaluation in the western part of Kushtia district of Bangladesh using vertical electrical sounding technique", ISH Journal of Hydraulic Engineering, 21:1, pp. 97-110, 2014. DOI:10.1080/09715010.2014.981679.

[10] R. A. Freeze and J. A. Cherry, "Groundwater", PrenticeHall, New Jersey, p. 6041979.

[11] P. A. Domenico and F. W. Schwartz, "Physical and Chemical Hydrogeology", John Willey and Sons, p. 824, 1990.

[12] C. W. Fetter, "Applied Hydrogeology", Fourth Edition, Prentice Hall, 2001.

[13] W. B. Harland, R. L. Armstrong, A. V. Cox, L. E. Craig, A. G. Smith and D. G. Smith, "A Geologic Time Scale", Cambridge University Press, p.263, 1990.

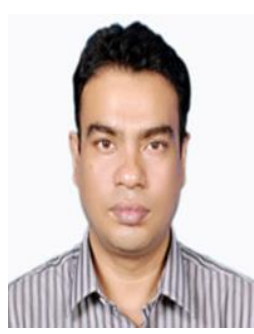

M. Shahinuzzaman was born in 1978. He received his Bachelor Degree (2000) and Master Degree (2001) from the department of Electrical and Electronic Engineering from Islamic University, Kushtia, Bangladesh. He received his Ph.D degree from the same department in 2019. From 2005-2008, he was Lecturer at the department of Electrical and Electronic Engineering, Islamic University, Kushtia, Bangladesh. From 2008-2016, he was Assistant Professor and from 2016 till now he has been working as an Associate Professor at the same department. His research interest includes geophysical science, environmental science, wireless communication and material science.

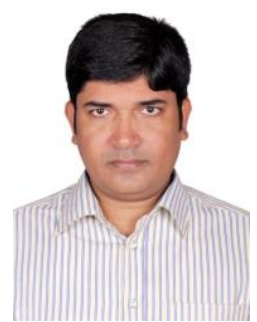

M. Nasir Uddin Khan was born in Jhenaidah in 1979. He received his Bachelor Degree (2000) and Master Degree (2001) from the department of Electrical and Electronic Engineering from Islamic University, Kushtia, Bangladesh. From 2005-2008, he was Lecturer at the department of Electrical and Electronic Engineering, Islamic University, Kushtia, Bangladesh. From 2008-2016, he was Assistant Professor and from 2016 till now he has been working as an Associate Professor at the same department. His research interest includes geophysical science, material science, wireless communication, machine learning.

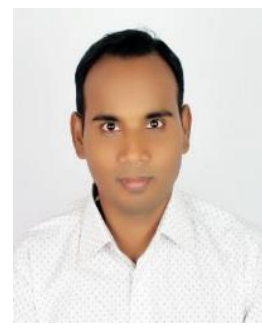

M. Khairul Islam was born in Kushtia in 1979. He received his Bachelor Degree (2000) and Master Degree (2001) from the department of Electrical and Electronic Engineering from Islamic University, Kushtia, Bangladesh. From 2005-2008, he was Lecturer at the department of Electrical and Electronic Engineering, Islamic University, Kushtia, Bangladesh. From 2008-2016, he 
was Assistant Professor and from 2016 till now he has been working as an Associate Professor at the same department. His research interest includes material science, biomedical engineering, geophysical science, environmental science and wireless communication.

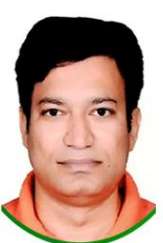

Md. Zahidul Islam was born in 1978. He has received his B.Sc. and M.Sc. degrees in 2000 and 2002 respectively from the Department of Applied Physics \& Electronic Engineering, University of Rajshahi (RU), Bangladesh. In 2003, he has joined as a Lecturer in the Department of Information and Communication Engineering, Islamic University (IU), Kushtia, Bangladesh. He was successfully awarded with $\mathrm{PhD}$ for his research on Visual Object Tracking System from the Department of Computer Engineering, Chonnam National University (CNU), South Korea in 2011. Dr. Islam has research interests like computer vision, 3D object, human and motion tracking and tracking articulated body, genetic algorithm etc. 